University of Wollongong

Research Online

Faculty of Social Sciences - Papers (Archive) Faculty of Arts, Social Sciences \& Humanities

2018

Low Levels of after School-Hours Social Interaction and Physical Activity of 5-7 Year Olds

Anita C. Bundy

University of Sydney

Lina Engelen

University of Wollongong, lengelen@uow.edu.au

Geraldine A. Naughton

Australian Catholic University

Shirley Wyver

Macquarie University

Follow this and additional works at: https://ro.uow.edu.au/sspapers

Part of the Education Commons, and the Social and Behavioral Sciences Commons

Research Online is the open access institutional repository for the University of Wollongong. For further information contact the UOW Library: research-pubs@uow.edu.au 


\title{
Low Levels of after School-Hours Social Interaction and Physical Activity of 5-7 Year Olds
}

\author{
Abstract \\ As part of a cluster randomized controlled trial (Bundy et al., 2017), the after school-hours activities of 5-7 \\ year old children were recorded by parents and other adult carers on four consecutive weekdays between \\ 3:30pm-7:00pm. Records of time use showed most time was spent indoors in activities involving low \\ levels of physical activity. The most-frequently-recorded activity was screen time, accounting for \\ approximately one quarter of all activities. Higher levels of physical activity were reported when children \\ were outdoors ( $19.5 \%$ of time) and/or with peers (9.58\%). If an adult was present, highest activity levels of \\ children occurred when the child was with a teacher/carer (6.07\%). Although concern is frequently raised \\ about children spending too much time in organized activities, these structured forms of out-of-school \\ choices accounted for only $8.09 \%$ of recordings. The results of the current study strengthen the evidence \\ base, supporting the need to optimise out-ofschool times with more developmentally important social \\ and physical contexts. We discuss ways in which context may support or inhibit opportunities physical \\ activity in after school-hours activities.
}

\section{Keywords}

activity, year, physical, interaction, social, school-hours, olds, after, 5-7, levels, low

\section{Disciplines}

Education | Social and Behavioral Sciences

\section{Publication Details}

Bundy, A., Engelen, L., Naughton, G. \& Wyver, S. (2018). Low Levels of after School-Hours Social Interaction and Physical Activity of 5-7 Year Olds. Asia-Pacific Journal of Research in Early Childhood Education, 12 (2), 79-92. 


\title{
Low Levels of after School-Hours Social Interaction and Physical Activity of 5-7 Year Olds
}

\author{
Anita Bundy \\ Lina Engelen \\ University of Sydney \\ Geraldine Naughton \\ Australian Catholic University \\ Shirley Wyver ${ }^{1)}$ \\ Macquarie University
}

\begin{abstract}
As part of a cluster randomized controlled trial (Bundy et al., 2017), the after school-hours activities of 5-7 year old children were recorded by parents and other adult carers on four consecutive weekdays between 3:30pm-7:00pm. Records of time use showed most time was spent indoors in activities involving low levels of physical activity. The most-frequently-recorded activity was screen time, accounting for approximately one quarter of all activities. Higher levels of physical activity were reported when children were outdoors (19.5\% of time) and/or with peers (9.58\%). If an adult was present, highest activity levels of children occurred when the child was with a teacher/carer $(6.07 \%)$. Although concern is frequently raised about children spending too much time in organized activities, these structured forms of out-of-school choices accounted for only $8.09 \%$ of recordings. The results of the current study strengthen the evidence base, supporting the need to optimise out-ofschool times with more developmentally important social and physical contexts. We discuss ways in which context may support or inhibit opportunities physical activity in after school-hours activities.
\end{abstract}

Keywords: outdoor play, social interaction, physical activity, sedentary

Corresponding author, ${ }^{1)}$ shirley.wyver@mq.edu.au 
The importance of young children's activities within and outside of school hours has received increasing recognition in recent years (Brussoni et al., 2015; Hyndman \& Lester, 2015). Concerns about children's physical, social, and emotional health are linked directly to the types of opportunities available during recess and outside of school hours. In particular, concerns target diminishing opportunities for free play (e.g. Milteer, Ginsburg, \& Mulligan, 2012). Internationally, increased prevalence in overweight and obesity underpins attention to modifiable lifestyle factors including children's low levels of physical activity (Ben-Sefer, Ben-Natan, \& Ehrenfeld, 2009; Murphy \& Demaio, 2018; Waters \& Baur, 2003). Recent findings of vitamin D deficiencies have also drawn attention to the amount of time spent indoors (Greer et al., 2007; Munns et al., 2006; Voortman et al., 2015). Concerns expressed about limitations in opportunities for physical activity include changes that are most likely to promote outdoor free play in context (Wyver et al., 2012). At the same time, however, a public perception exists of children being overscheduled and having too much activity, especially, in organized sports (e.g. Hunter, 2013). Yet in Australia, for example, national data collected in 2015 to 2016 showed that 5-8 year olds spent a median time of 53 minutes participating in sport during the past two weeks (Australian Sports Commission, 2016), indicating that organized sport is not excessive and not interfering with opportunities for other leisure time pursuits.

International reviews demonstrate declines in children's physical activity (Rowlands, 2018), raising concerns relating to children's long term health. A range of studies, including interventions, have examined physical activity and sedentary behaviours in the context of school play (e.g. Bundy et al., 2017; Hyndman et al., 2014; O'Dwyer et al., 2013). Nonetheless, what happens outside of school hours has an important contribution to the overall amount of time children spend being physically active or engaging in sedentary behaviours (Arundell, Hinkley, Veitch, \& Salmon, 2015). Interventions promoting activity at recess may not easily generalize to after-school (Bundy et al., 2017; Remmers, van Kann, Thijs, de Vries, \& Kremers, 2016). A recent systematic review noted that children spend a greater amount of time in sedentary behaviours after school than at recess (Arundell, Fletcher, Salmon, Veitch, \& Hinkley, 2016). The researchers further noted that children were less likely to be sedentary in after-school care than in other contexts and conjectured that opportunities for free play, sport, and time with friends may contribute to the difference. 
Some researchers remain concerned that the current focus on children's play is driven by a health agenda related to obesity, potentially distorting the importance of play (Alexander, Frohlich, \& Fusco, 2014a, 2014b). It is essential to acknowledge that children express interest in outdoor play independently of adults' health focus. Parents in the Longitudinal Study of Australian Children (LSAC) were asked about children's preferences for active pastimes (such as running and kicking a ball) or inactive pastimes (such as drawing, watching TV, and playing with toys in one place). Just over $40 \%$ of parents of this cohort of 6-7 year-olds reported their child was equally likely to choose active or inactive pastimes when given a choice of how to spend their free time. Around $30 \%$ had a preference for active pastimes and a similar percentage for inactive pastimes (Australian Institute of Family Studies, 2008). This suggests that, given free choice, this sample of children would spend a substantial proportion of their time in active pastimes.

Furthermore, a recent qualitative study found children aged 4-6 years would rather play outside with friends than engage in screen time activities (Hatzigianni, 2014). Importantly, outdoor play is positively associated with social skills whereas screen time involving television and DVDs is adversely associated with social engagement (Hinkley, Brown, Carson, \& Teychenne, 2018).

The present study contributes to current understanding of after-hours school activities by examining children's physical activity within social contexts. The study was designed to profile children's activity after school hours, including three things: (1) who they are with; (2) whether they were indoors or outdoors; and (3) their levels of physical movement, movement intensity, and involvement.

\section{Method}

Data were collected as part of a larger study within the Sydney Playground Project (SPP). SPP is a cluster randomized controlled trial of an outdoor play intervention program. A feature of the intervention program is the introduction of loose materials such as car tyres, milk crates, and hay bales into the school playground. Pilot testing of the intervention found it to be a low-cost and easy-to-implement approach that led to increases in children's play, 
measured by Skard and Bundy (2008)'s Test of Playfulness (ToP), and physical activity (measured using accelerometers) (Bundy et al., 2008; Bundy et al., 2009). More details of the Sydney playground project protocol can be found in the study of Bundy et al. (2011). After school-hours activity, data were collected before and after the intervention. For the present study, we used only baseline data as posttest data that may not be generalizable to children and not be involved in the Sydney playground project intervention.

\section{Participants}

A total of 221 children (103 girls, 118 boys) with a mean age of 5.9 years were recruited from K-1 classes at 12 Catholic education primary schools. Families of most of the children were of moderate socioeconomic status. The schools' Socio-Economic Indexes for Areas (SEIFA) (Australian Bureau of Statistics, 2013) ratings were between 883.40 and 1094.16. Only one school was in the lowest $15 \%$ (SEIFA scores less than 900) and no schools were in the upper 15\% (scores above 1100). Australian Early Development Index (AEDI) scores for four schools indicated that more than $10 \%$ of attending children were developmentally vulnerable in two or more areas (Commonwealth of Australia, 2014-2015). The recruitment process involved random selection of children for participation. Schools were presented with a set of randomly generated numbers and asked to provide consent information to the first 20 parents of children whose names were matched with the numbers on the class lists (e.g. number 3 indicated the third child on the class list). In cases where consent was not received for all 20 children, additional parents were consulted using the same random numbers procedure. A total of 226 parents provided consent with four later withdrawing from the study (1 boy, 3 girls) and one girl's absence from school excluding her from participation.

\section{Recording After-School Activity}

Directly observed activity was recorded by an adult who was caring for the child after school. A total of $92 \%$ of recordings were made by a parent of the child, $2 \%$ by a grandparent, $0.5 \%$ by a teacher, $2.5 \%$ by another carer, and $3 \%$ by someone else. The 
activity questionnaire included multiple choice questions to determine: (1) who was recording the information; (2) what the child was doing; (3) who the child was with; and (4) whether they were indoors or outdoors. Three Visual Analogue Scale (VAS) slider questions were used to estimate the following: (1) activity level; (2) frequency of movement; and (3) intensity of involvement in an activity. For the VAS questions, 0 indicated the lowest level and 100 indicated the highest level. In a related study involving 20 parent-child dyads, we attempted to validate the reported activity levels with an accelerometry (Lau, Engelen, \& Bundy, 2013). The results of that study showed that parents overestimated the level of activity in the majority of cases.

Questionnaire items were developed from the literature on children's after school activities and in conjunction with researchers working with young children and parents of children of the target age. The questionnaires were delivered using a study-specific app uploaded onto Palm Pilots (Z22). Palm Pilots are handheld mobile electronic devices or personal digital assistants similar to smartphones in size and weight. The Palm Pilots were set to provide an auditory signal indicating a questionnaire was ready to complete. A questionnaire was made available at three random after-school times on four consecutive week days between $3: 30 \mathrm{pm}-7: 00 \mathrm{pm}$ (12 questionnaires in total). This methodology represents a simple version of experience sampling (Hektner, Schmidt, \& Csikszentmihalyi, 2007), a methodology shown to be valid and reliable for capturing in-the-moment experiential data.

Pilot testing indicated completion time for questionnaires was between $30-180$ seconds; shorter durations usually occur as the respondent became familiar with the questionnaire items, which were always the same. The Palm Pilots were set to allow for interruptions during completion of the questionnaires. At each school, parents met with researchers to discuss the project and parents were given instructions and practice in using the Palm Pilots. Written instructions were provided to parents who were unable to attend these sessions. Parents were responsible for training non-parent respondents caring for children in afterschool hours. Of the 2504 questionnaires delivered, 1545 (61.7\%) were completed. Reasons for missing some, or sometimes all of the questionnaires, included not hearing the signal, forgetting to have the device close by, driving or similarly occupied when the questionnaire became available and a member of the family playing with the device and wiping the 
program. Some questionnaires were only partially completed due to interruptions such as telephone calls and children requesting help or attention.

\section{Results}

Results from the multiple choice questionnaire items are presented as percentage of recordings calculated by dividing the number of responses to a specific item (e.g. child is indoors) by the total number of responses (generally 1545 - slightly less for some questions where there was missing data). Where activity levels are reported, these are from a VAS slider question (e.g. "Is the child moving?") with 0 indicating 'not at all' and 100 indicating 'a lot'. A one-way ANOVA failed to show differences between reported activity of boys $(\mathrm{M}=50.56, S D=31)$ and girls $(\mathrm{M}=48.56, S D=30.29)(F=1.6, p=0.21)$. Children were indoors for $80.5 \%$ of recordings ( $81.2 \%$ girls, $80 \%$ boys). Recorded activity level was greater when outdoors ( $\mathrm{M}=70.01, S D=29.99)$ than indoors $(\mathrm{M}=44.71, S D=28.76)(F=179.83, p<0.000)$.

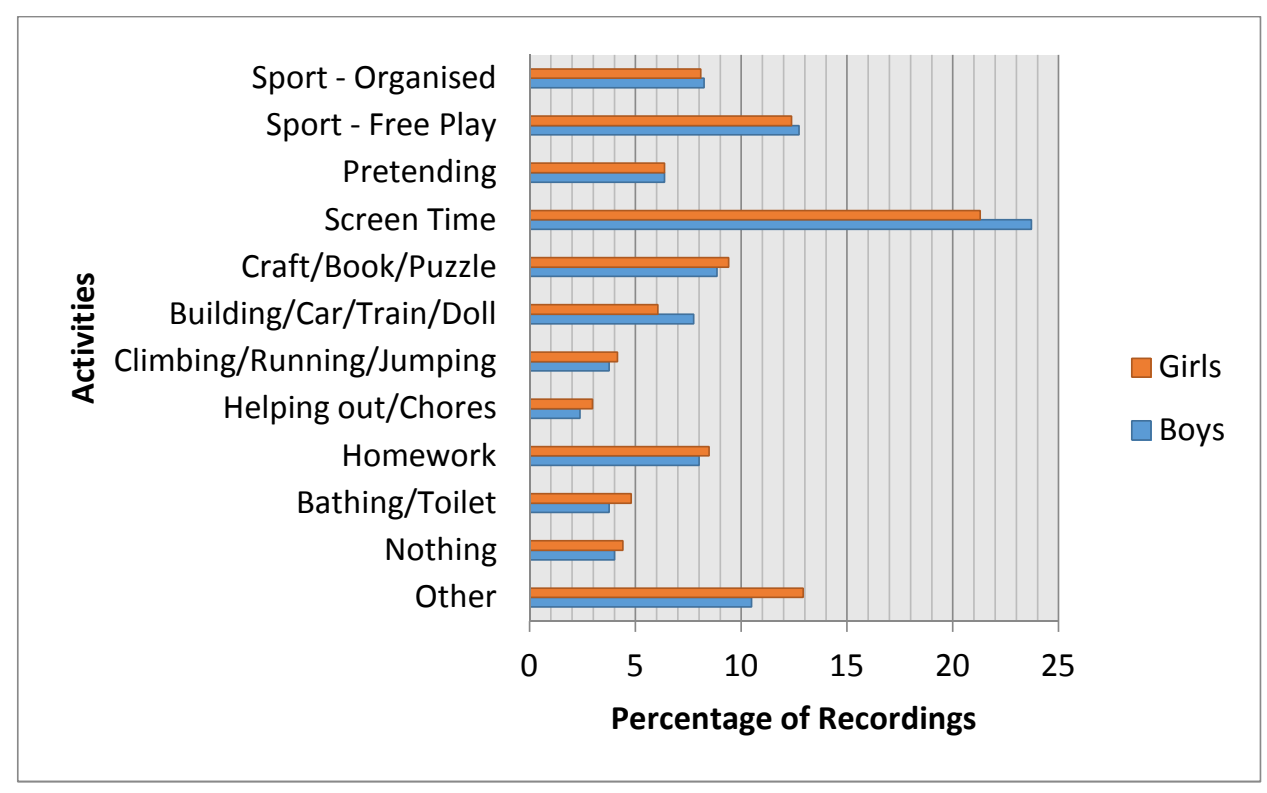

Figure 1. Percentage of Recordings by Gender for the Question "What is the Child Doing Now?" 
As can be seen in Figure 1, children were recorded in organized sport on $8.1 \%$ of occasions ( $7.9 \%$ girls, $8.2 \%$ boys). The most frequent recording was screen time $(21.3 \%$ overall, $18.6 \%$ girls, $23.7 \%$ boys). Figure 2 shows that screen time was amongst the activities with the lowest rating for physical activity whereas organized sport was the highest. Children were eating (meals or snacks) on $25.6 \%$ of recorded occasions $(28.0 \%$ girls, $23.5 \%$ boys).

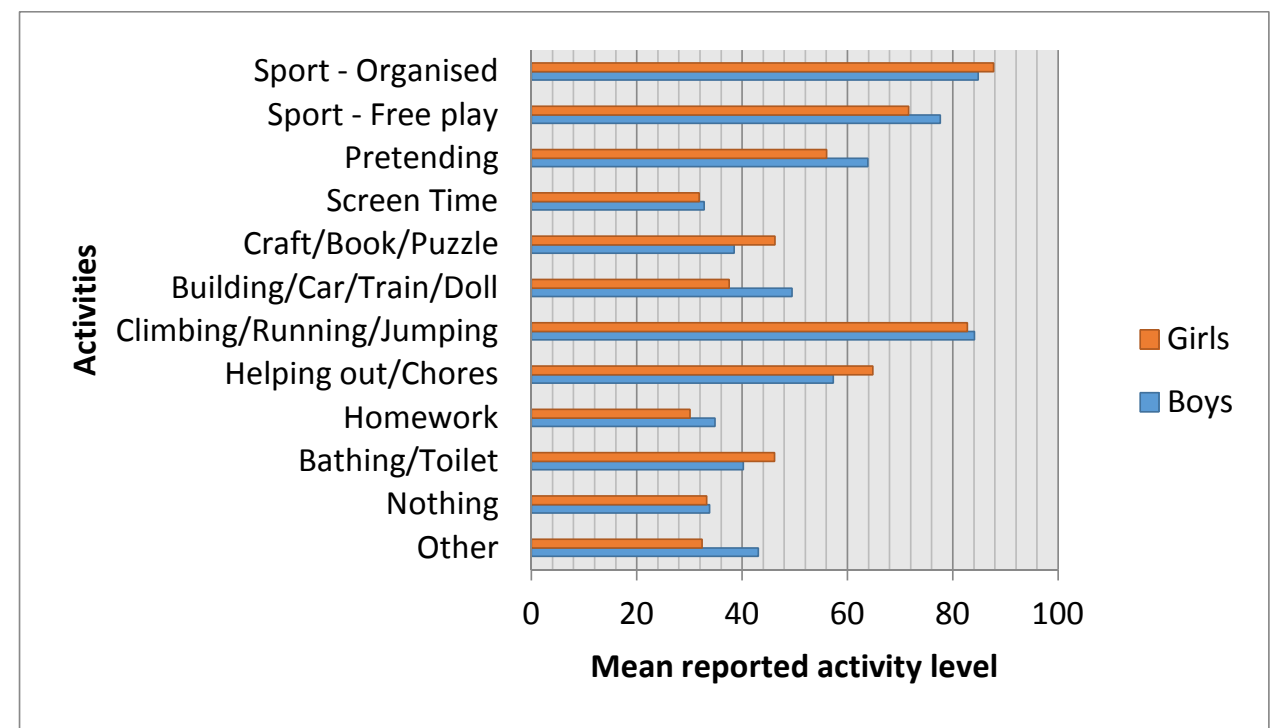

Figure 2. Mean Reported Activity Level for Each the After-School Activities by Gender

On $37.5 \%$ of occasions, children were with adults ( $38.8 \%$ girls, $36.4 \%$ boys). Activity level, frequency of movement, and intensity of involvement in activities were reported as highest for both genders when the child was with a teacher/carer (see Table 1). If they were with another child, it was more likely to be a sibling (30.8\% overall, $29.2 \%$ girls, $32.3 \%$ boys) than a friend $(9.6 \%$ overall, $10.1 \%$ girls, $9.1 \%$ boys). Activity, frequency of movement, and intensity of involvement were recorded as highest for both genders when the child was with a friend or various children (and possibly pets) (see Table 2). 
Table 1. Amount of Movement, Movement Frequency, and Involvement Intensity when with Adults (Means and Standard Deviations)

\begin{tabular}{cccccccc}
\hline & & \multicolumn{3}{c}{ Girls } & \multicolumn{3}{c}{ Boys } \\
\cline { 2 - 8 } & & $\begin{array}{c}\text { Amount of } \\
\text { Movement }\end{array}$ & $\begin{array}{c}\text { Movement } \\
\text { Frequency }\end{array}$ & $\begin{array}{c}\text { Involvement } \\
\text { Intensity }\end{array}$ & $\begin{array}{c}\text { Amount of } \\
\text { Movement }\end{array}$ & $\begin{array}{c}\text { Movement } \\
\text { Frequency }\end{array}$ & $\begin{array}{c}\text { Involvement } \\
\text { Intensity }\end{array}$ \\
\hline Mother & Mean & 43.40 & 50.33 & 65.08 & 47.09 & 57.48 & 71.35 \\
& $S D$ & 28.10 & 25.98 & 24.85 & 30.98 & 28.19 & 24.38 \\
\hline Father & Mean & 57.52 & 57.91 & 67.76 & 61.91 & 59.31 & 76.18 \\
& $S D$ & 31.30 & 24.64 & 21.72 & 31.27 & 28.87 & 19.43 \\
\hline Teacher/Carer & Mean & 77.91 & 73.51 & 74.86 & 78.02 & 78.98 & 83.35 \\
& $S D$ & 26.76 & 25.39 & 18.58 & 23.62 & 18.62 & 14.89 \\
\hline Other Family & Mean & 58.02 & 52.02 & 70.35 & 66.95 & 65.69 & 70.69 \\
& $S D$ & 30.77 & 26.14 & 21.14 & 25.39 & 24.52 & 22.06 \\
\hline Combination & Mean & 60.98 & 55.71 & 69.88 & 58.81 & 59.63 & 71.03 \\
& $S D$ & 27.79 & 27.70 & 20.82 & 30.27 & 27.89 & 24.09 \\
\hline No Adult & Mean & 44.24 & 48.16 & 61.65 & 44.85 & 50.92 & 67.58 \\
& $S D$ & 29.10 & 27.59 & 23.94 & 29.82 & 28.25 & 21.26 \\
\hline
\end{tabular}

*possible range $0-100$

Table 2. Amount of Movement, Movement Frequency, and Involvement Intensity when with Children or Pets (Means and Standard Deviations)

\begin{tabular}{cccccccc}
\hline & & \multicolumn{3}{c}{ Girls } & & \multicolumn{2}{c}{ Boys } \\
\cline { 3 - 8 } & & $\begin{array}{c}\text { Amount of } \\
\text { Movement }\end{array}$ & $\begin{array}{c}\text { Movement } \\
\text { Frequency }\end{array}$ & $\begin{array}{c}\text { Involvement } \\
\text { Intensity }\end{array}$ & $\begin{array}{c}\text { Amount of } \\
\text { Movement }\end{array}$ & $\begin{array}{c}\text { Movement } \\
\text { Frequency }\end{array}$ & $\begin{array}{c}\text { Involvement } \\
\text { Intensity }\end{array}$ \\
\hline Sibling & Mean & 56.17 & 56.69 & 68.58 & 58.45 & 60.91 & 73.53 \\
& $S D$ & 28.53 & 24.86 & 21.50 & 28.96 & 26.39 & 19.70 \\
\hline Friend & Mean & 71.26 & 66.16 & 70.93 & 73.37 & 73.15 & 76.59 \\
& $S D$ & 25.01 & 23.54 & 20.46 & 29.89 & 24.62 & 19.57 \\
\hline Other Family & Mean & 35.44 & 47.56 & 53.00 & 65.54 & 67.68 & 71.93 \\
& $S D$ & 36.65 & 33.45 & 29.99 & 32.73 & 24.67 & 24.06 \\
\hline Pet & Mean & 55.09 & 56.09 & 67.00 & 58.30 & 59.30 & 90.33 \\
& $S D$ & 28.15 & 23.63 & 15.09 & 44.20 & 45.90 & 11.59 \\
\hline Combination & Mean & 65.55 & 63.52 & 69.21 & 75.15 & 72.85 & 76.81 \\
& $S D$ & 24.15 & 24.22 & 17.95 & 21.79 & 23.10 & 20.34 \\
\hline No Child/Pet & Mean & 38.79 & 44.07 & 60.60 & 38.93 & 46.92 & 65.80 \\
& $S D$ & 28.21 & 27.81 & 24.92 & 27.53 & 27.80 & 22.46 \\
\hline
\end{tabular}

As activity was higher when children were outdoors, we checked to determine whether the social partners associated with higher activity levels were more likely to be children. When reading these percentages, it is important to recall that children were reported to be outdoors on fewer than $20 \%$ of occasions. Of those outdoor occasions, the highest 
percentage of social partners was other children (i.e. Friends: $45.2 \%$ girls, $63.5 \%$ boys) When playing with adults, girls were most likely to be outdoors with their father (30.3\%) and boys with a teacher/carer (57.1\%).

\section{Discussion}

We found a close relationship between physical and social contexts and activity level. In particular, children's outdoor environments were associated with higher levels of physical activity when with friends or a teacher/carer. Unfortunately, these were low frequency contexts for children. Most often, children were indoors, engaging in screen time, and relatively inactive. Clearly, the design of the present study does not enable conclusions about causality. Nonetheless, the findings may be useful in considering a change in balance of existing behaviours to promote physical activity (i.e. more time outdoors).

Our results contribute to a growing body of research examining children's after-school activities. In particular, it shows that children were spending the highest proportion of time with screens, which was associated with inactivity. In addition, the contextual information available through sampling methods is valuable for understanding the relationship between activity type and activity levels (Engelen et al., 2015). Also, as noted in the introduction, children in previous research have expressed a preference for outdoor play over screen time (Hatzigianni, 2014). Tackling difficulties related to children's access to high quality afterschool hours activities is complex and requires a multidisciplinary approach. For example, Freeman and Tranter (2012) note that children are increasingly unwelcome in spaces that were traditionally used for play, including both built and natural spaces. They argue that "children's visibility in many urban areas is conspicuous by its absence" (p. 11). Better urban planning is required to enable children to engage in play and learning in public outdoor spaces (Wyver et al., 2017). The perception of children in public spaces as both dangerous (or at least a nuisance) and vulnerable to crime also needs to be addressed as these misunderstandings limit children's autonomy and restrict opportunities for active outdoor play and learning (Little, 2012).

We did not find evidence that children were overscheduled in sports or other activities. 
Our results concur with those of the Australian Sports Commission (2016) and suggest that the perception of children being overscheduled may be misguided. Nonetheless, our method of data collection may have meant that organized sports or similar activities were underrepresented. For example, it is possible that some of our missing data relates to scheduled sports when parents/carers are not with their child and, therefore, not responding to the surveys.

Missing data was a problem in this study as it has been in other studies of children's time use (e.g. Fiorini \& Keane, 2014). In this study, some parental activities, such as driving, would have prevented responding to the questionnaire. Clearly, there are limitations in use of in-the-moment surveys to obtain time use data. However, a particular advantage of this novel, non-intrusive, and developmentally appropriate instrument was that we captured a profile of play not subject to parental memory.

Another limitation in this study is that the children's reported activity levels are likely to be overestimated. As previously noted, we found that parents highly overestimated their children's activity levels compared with accelerometers (Lau et al., 2013). However, here we were interested in comparing relative levels of activity indoors and outdoors rather than in precise measures of activity level. Our previous study showed us that parents' estimates, while exaggerated, were in proportion to the setting; that is, they were not erratic.

The instrument we used was new and requires further validation. Although some initial work was done in the study of Lau et al. (2013), further work, such as comparing researcher observation to parent/carer recording, is needed. Future investigations should also consider the rapid increase in technologies currently available (see Loveday, Sherar, Sanders, Sanderson, \& Esliger, 2015).

\section{References}

Alexander, S. A., Frohlich, K. L., \& Fusco, C. (2014a). Playing for health? Revisiting health promotion to examine the emerging public health position on children's play. Health Promotion International, 29(1), 155-164. doi:10.1093/heapro/das042

Alexander, S. A., Frohlich, K. L., \& Fusco, C. (2014b). Problematizing "Play-for-Health" discourses through children's photo-elicited narratives. Qualitative Health Research, 
Low Levels of after School-Hours Social Interaction and Physical Activity of 5-7 Year Olds

24(10), 1329-1341. doi:10.1177/1049732314546753

Arundell, L., Fletcher, E., Salmon, J., Veitch, J., \& Hinkley, T. (2016). A systematic review of the prevalence of sedentary behavior during the after-school period among children aged 5-18 years. International Journal of Behavioral Nutrition and Physical Activity, 13(93). doi:10.1186/s12966-016-0419-1

Arundell, L., Hinkley, T., Veitch, J., \& Salmon, J. (2015). Contribution of the after-school period to children's daily participation in physical activity and sedentary behaviours. PLOS ONE, 10(10), 1-11. doi:10.1371/journal.pone.0140132

Australian Bureau of Statistics (ABS). (2013). SEIFA 2011. Retrieved from http://www.abs.gov.au/websitedbs/censushome.nsf/home/seifa2011?opendocument\&n avpos $=260$

Australian Institute of Family Studies. (2008). Growing up in Australia: The longitudinal study of Australian children: Annual Report 2006-2007. Retrieved from http://data.growingupinaustralia.gov.au/pubs/ar/ar200607/annualreport2006-07.pdf

Australian Sports Commission. (2016). AusPlay: Participation data for the sport sector.

Canberra: Australian Sports Commission. Retrieved from https://www.ausport.gov.au/_data/assets/pdf_file/0007/653875/34648_AusPlay_sum mary_report_accessible_FINAL_updated_211216.pdf

Ben-Sefer, E., Ben-Natan, M., \& Ehrenfeld, M. (2009). Childhood obesity: Current literature, policy and implications for practice. International Nursing Review, 56(2), 166-173. doi:10.1111/j.1466-7657.2008.00708.x

Brussoni, M., Gibbons, R., Gray, C., Ishikawa, T., Sandseter, E. B. H., Bienenstock, A., ... Pickett, W. (2015). What is the relationship between risky outdoor play and health in children? A systematic review. International Journal of Environmental Research and Public Health, 12(6), 6423-6454. doi:10.3390/ijerph120606423

Bundy, A., Engelen, L., Wyver, S., Tranter, P., Ragen, J., Bauman, A., Baur, L., Schiller, W., Simpson, J. M., Niehues, A. N., Perry, G., Jessup, G., \& Naughton, G. (2017). Sydney playground project: A cluster-randomized trial to increase physical activity, play, and social skills. Journal of School Health, 87(10), 751-759. doi:10.1111/josh. 12550

Bundy, A. C., Luckett, T., Naughton, G. A., Tranter, P. J., Wyver, S. R., Ragen, J., ... Spies, 
G. (2008). Playful interaction: Occupational therapy for all children on the school playground. American Journal of Occupational Therapy, 62(5), 522-527. doi:10.5014/ajot.62.5.522

Bundy, A. C., Luckett, T., Tranter, P. J., Naughton, G. A., Wyver, S. R., Ragen, J., \& Spies, G. (2009). The risk is that there is "no risk": A simple, innovative intervention to increase children's activity levels. International Journal of Early Years Education, $17(1), 33-45$.

Bundy, A. C., Naughton, G., Tranter, P., Wyver, S., Baur, L., Schiller, W., .. Brentnall, J. (2011). The Sydney playground project: Popping the bubblewrap-unleashing the power of play: A cluster randomized controlled trial of a primary school playgroundbased intervention aiming to increase children's physical activity and social skills. BMC Public Health, 11, 1-9. doi:10.1186/1471-2458-11-680

Commonwealth of Australia. (2014-2015). Australian early development census: Data explorer. Retrieved from http://www.aedc.gov.au/data/data-explorer

Engelen, L., Bundy, A. C., Lau, J., Naughton, G., Wyver, S., Bauman, A., \& Baur, L. (2015). Understanding patterns of young children's physical activity after school - It's all about context: A cross-sectional study. Journal of Physical Activity \& Health, 12(3), 335-339. doi:10.1123/jpah.2013-0153

Fiorini, M., \& Keane, M. P. (2014). How the allocation of children's time affects cognitive and noncognitive development. Journal of Labor Economics, 32(4), 787-836.

Freeman, C., \& Tranter, P. (2012). Children and their urban environment: Changing worlds. London: Routledge.

Greer, R. M., Rogers, M. A., Bowling, F. G., Buntain, H. M., Harris, M., Leong, G. M., \& Cotterill, A. M. (2007). Australian children and adolescents with type 1 diabetes have low vitamin D levels. Medical Journal of Australia, 187(1), 59-60.

Hatzigianni, M. (2014). "I like computers but my favourite is playing outside with my friends": Young children's beliefs about computers. International Research in Early Childhood Education, 5(1), 83-102.

Hektner, J. M., Schmidt, J. A., \& Csikszentmihalyi, M. (2007). Experience sampling method: Measuring the quality of everyday life. Thousand Oaks, CA: Sage.

Hinkley, T., Brown, H., Carson, V., \& Teychenne, M. (2018). Cross sectional associations 
of screen time and outdoor play with social skills in preschool children. PLOS ONE, 13(4), 1-15. doi:10.1371/journal.pone.0193700

Hunter, K. (2013, February 18). 'In our house, it's just one sport per kid per term.' Retrieved from https://www.mamamia.com.au/how-many-is-too-many-activities-forkids/

Hyndman, B. P., Benson, A. C., Ullah, S., Telford, A., Butcher, K., Sallis, J., ... Stratton, G. (2014). Evaluating the effects of the Lunchtime Enjoyment Activity and Play (LEAP) school playground intervention on children's quality of life, enjoyment and participation in physical activity. BMC Public Health, 14(1), 1-16. doi:10.1186/14712458-14-164

Hyndman, B. P., \& Lester, L. (2015). The relationship between elementary school children's enjoyment of school playground activities and participation in physical activity during lunchtime recess. Children Youth and Environments, 25(1), 80-99. doi:10.7721/chilyoutenvi.25.1.0080

Lau, J., Engelen, L., \& Bundy, A. (2013). Parents' perceptions of children's physical activity compared to two electronic diaries. Pediatric Exercise Science, 25(1), 124-137. doi:10.1123/pes.25.1.124

Little, H. (2012). Contradictory images of children: Growing up in a dangerous (?) world. In S. Wyver, \& P. Whiteman (Eds.), Children and childhoods 2: Images of childhood (pp. 88-104). Newcastle upon Tyne: Cambridge Scholars Publishing.

Loveday, A., Sherar, L. B., Sanders, J. P., Sanderson, P. W., \& Esliger, D. W. (2015) Technologies that assess the location of physical activity and sedentary behavior: A systematic review. Journal of Medical Internet Research, 17(8), 1-28. doi:10.2196/jmir.4761

Milteer, R. M., Ginsburg, K. R., \& Mulligan, D. A. (2012). The importance of play in promoting healthy child development and maintaining strong parent-child bond: Focus on children in poverty. Pediatrics, 129(1), e204-e213. doi:10.1542/peds.2011-2953

Munns, C., Zacharin, M. R., Rodda, C. P., Batch, J. A., Morley, R., Cranswick, N. E., ... Grover, S. R. (2006). Prevention and treatment of infant and childhood vitamin D deficiency in Australia and New Zealand: A consensus statement. Medical Journal of Australia, 185(5), 268-272. 
Murphy, L., \& Demaio, A. R. (2018). Understanding and removing barriers to physical activity: One key in addressing child obesity. British Journal of Sports Medicine. doi:10.1136/bjsports-2017-098546

O’Dwyer, M. V., Fairclough, S. J., Ridgers, N. D., Knowles, Z. R., Foweather, L., \& Stratton, G. (2013). Effect of a school-based active play intervention on sedentary time and physical activity in preschool children. Health Education Research, 28(6), 931942. doi:10.1093/her/cyt097

Remmers, T., van Kann, D., Thijs, C., de Vries, S., \& Kremers, S. (2016). Playability of school-environments and after-school physical activity among 8-11 year-old children: Specificity of time and place. International Journal of Behavioral Nutrition and Physical Activity, 13(1), 1-10. doi:10.1186/s12966-016-0407-5

Rowlands, A. V. (2018). Physical activity, inactivity, and health during youth-The year that was 2017. Pediatric Exercise Science, 30(1), 54-57. doi:10.1123/pes.2017-0296

Skard, G., \& Bundy, A. (2008). Test of playfulness. In L. D. Parham, \& L. S. Fazio (Eds.), Play in occupational therapy for children ( $2^{\text {nd }}$ ed.) (pp. 71-93). Missouri: Mosby Elsevier.

Voortman, T., van den Hooven, E. H., Heijboer, A. C., Hofman, A., Jaddoe, V. W., \& Franco, O. H. (2015). Vitamin D deficiency in school-age children is associated with sociodemographic and lifestyle factors. The Journal of Nutrition, 145(4), 791-798. doi:10.3945/jn.114.208280

Waters, E. B., \& Baur, L. A. (2003). Childhood obesity: Modernity's scourge. Medical Journal of Australia, 178(9), 422-423.

Wyver, S., Kent, J., Tranter, P., Naughton, G., Engelen, L., Bundy, A., \& Tara, K. (2017). Urban environments and outdoor learning. In H. Little, S. Elliott, \& S. Wyver (Eds.), Outdoor learning environments: Spaces for exploration, discovery and risk-taking in the early years (pp. 262-274). Sydney: Allen \& Unwin.

Wyver, S., Tranter, P., Sandseter, E. B. H., Naughton, G., Little, H., Bundy, A., Ragen, J., \& Engelen, L. (2012). Places to play outdoors: Sedentary and safe or active and risky? In P. Whiteman, \& K. de Gioia (Eds.), Children and childhoods: Contemporary perspectives, places and practices (pp. 85-107). Newcastle upon Tyne: Cambridge Scholars Publishing. 